\section{O processo histórico da atividade apícola entre os camponeses do Macizo Colombiano: um estudo de caso no sul da Colômbia, La Vega, Cauca ${ }^{1}$.}

Diana Carolina Cadena Bastidas Vanilde Ferreira de Souza-Esquerdo ${ }^{3}$

Resumo: Aregião do Macizo Colombiano representa a diversidade biológica e cultural, é nesta região onde se gestam sistemas produtivos caraterísticos das comunidades camponesas, percebe-se nessa região a manutenção de práticas camponesas. As relações presentes entre os camponeses são familiares e de vizinhança, todas estas envolvidas diretamente com o trabalho na terra, é por esta razão que o presente artigo tem como objetivo analisar o processo histórico do "surgimento" da atividade apícola, a partir de narrações de um ator de um grupo de camponeses do Sudoeste colombiano organizado na Asociación de Apicultores del Macizo Colombiano - APIMACIZO, e como a partir desta prática produtiva se estabelecem as relações sociais neste grupo associativo.

Palavras-chave: Camponês; Memória; Apicultura.

Abstract: The Macizo Colombiano region represents biological and cultural diversity; in this region where the productive systems characteristic of the peasant communities is found, the management of these peasant practices is observed. The relationships that are presented among peasants are family and neighbor relationships, all are related to work with the land. It is for this reason that the present study aims to analyze the historical process of the "appearance" of the beekeeping activity. From some narratives of an actor from a group of peasants from the southwestern Colombian organized in the Asociación de Apicultores del Macizo Colombiano- APIMACIZO and

'Este trabalho faz parte da dissertação de mestrado da primeira autora, com orientação da segunda autora e foi apresentado na VIII Jornada de Estudos em Assentamentos Rurais, em junho de 2017.- Grupo de trabalho 5 -Questão Agrária e Movimentos Sociais do Campo.

${ }^{2}$ Centro de Ciências Agrárias da Universidade Federal de São Carlos- PPGADR/UFSCAR - Centro de Ciências Agrárias da Universidade Federal de São Carlos- Bolsista CAPES. E-mail: kdnita20@gmail.com

${ }^{3}$ Faculdade de Engenharia Agrícola da Universidade Estadual de Campinas - Feagri/Unicamp. E-mail: vanilde esquerdo@feagri.unicamp.br how starting from this practice; establishes social relations of this group.

Keywords: Peasant; Memory; Beekeeping.

\section{Introdução}

Alguns dados sobre a população rural na Colômbia afirmam que em $2015,24 \%$ da população colombiana era considerada rural, embora em $75 \%$ do território nacional se estabelecem relações próprias de sociedades rurais (PNUD, 2011); além disso, a participação da economia campesina na agricultura continua sendo da ordem de 70\% (FORERO et al, 2010), evidenciando a importância e atuação de um setor da população no desenvolvimento do país, que muitas vezes não é reconhecido como indivíduo cultural e de desenvolvimento ${ }^{4}$.

Um dos grandes questionamentos que se apresentam em diferentes momentos nos estudos sobre o mundo rural, têm sido a persistência do campesinato, contrariamente a predições de distintos setores que anunciavam seu desaparecimento por causa da "modernidade", do desdobramento da revolução verde, entre outros aspectos. A respeito sobre esse fato Fals Borda (2002: 12B) afirma:

La clásica vocación campesina por la tierra para la utilización de los recursos naturales básicos que tanto abundan en Colombia, especialmente para producir comida, no ha desaparecido con el impacto de la modernidad capitalista ni con el de la nueva tecnología.

E se o campesinato não foi extinto, as relações com a terra, o trabalho, a família e a vizinhança também não desapareceram. O presente artigo tem por objetivo analisar o processo histórico do "surgimento" da atividade apícola num grupo de camponeses do Sudoeste colombiano, e como a partir dessa prática produtiva se estabelecem as relações sociais deste grupo do município de La Vega-Cauca, que estão organizados na Asociación de Apicultores del Macizo Colombiano-APIMACIZO.

Nosso trabalho têm como foco de estudo uma das populações situadas no estado do Cauca, o grupo de camponeses do município de La Vega, que desde 2007 encontram-se agremiados na Asociación de Apicultores del

${ }^{4}$ Carlos Salgado é um dos autores que retoma a discussão na Colômbia sobre o reconhecimento dos direitos dos camponeses, é por essa razão que sua discussão é dada sobre "el centro del problema es el reconocimiento del sujeto"(p.15), "desprovisto de reconocimientos elementales como el de ser sujeto cultural y del desarrollo"(p.14), "Un sujeto social desvalorizado suele no ser reconocido socialmente y sufre un daño severo en la construcción de su propia subjetividad" (p.14). 
Macizo Colombiano- APIMACIZO. Como vamos expor, esta associação é resultado de um processo histórico onde convergem vários atores tanto locais como externos à comunidade, que não só tem permitido um desenvolvimento econômico do grupo de camponeses aí envolvidos, como também criouse um vínculo entre uma atividade produtiva específica -apícola- e o ser camponês.

A discussão está abordada em quatro partes, além desta introdução. Inicialmente, apresenta-se uma abordagem histórica do povo do Macizo, a segunda parte está focada nas narrações de um associado da APIMACIZO, sujeito que reconstruiu uma referência em relação ao tempo e aos fatos que permitiram a inserção da apicultura como prática na região, na sequência faz-se um destaque e análise das relações entre a prática produtiva e o ser camponês, que é reivindicada pelo grupo de pessoas agremiadas na associação. Finalizamos tecendo algumas considerações sobre o presente estudo. Assim, com este relato do mel apresentamos os diferentes períodos históricos do povo do Macizo, bem como reconstruímos o primeiro momento histórico da apicultura neste grupo de camponeses, que pelas palavras de Mintz se apresentam como relevantes na introdução desta exposição: "los fenómenos sociales son históricos por naturaleza de modo que las relaciones entre acontecimientos en un "momento" no pueden abstraerse nunca de su panorama pasado y futuro" (1996, p. 28).

\section{Objetivos}

Geral

- De maneira geral, este trabalho objetiva analisar o processo histórico do "surgimento" da atividade apícola num grupo de camponeses agremiados na Associação de Apicultores do Macizo ColombianoAPIMACIZO, localizada no município de Vega, departamento de Cauca, Colômbia,

\section{Específico}

- Reconstruir a história da apicultura na APIMACIZO.

- Analisar a introdução da apicultura na vida dos camponeses da APIMACIZO.

- Descrever a relações familiares presentes na comunidade.

\section{Metodologia}

\section{Área do estudo}

Colômbia ${ }^{5}$ é um país caracterizado pela grande diversidade ${ }^{6}$ biológica onde se misturam diferentes topografias com variedades de culturas, sendo exemplo disso a região denominada como Macizo Colombiano, a qual é definida como um "complexo geohidrológico que conta com uma alta biodiversidade e em conjunto, capta, armazena e regula a água, que dá lugar aos nascimentos dos rios importantes na vida y economia do país" (IDEAM, 1999, p.2).

Além disso, é um complexo ecossistêmico que abrange uma grande parte dos departamentos do sudoeste colombiano, como são os do Cauca, Caquetá, Huila, Nariño, Putumayo, Tolima e Valle del Cauca, e como tal, se caracteriza não só pela importância geográfica, biológica e ecológica, senão também pela sua diversidade cultural.

Figura 1. Localização geográfica do município de La Vega, Cauca.

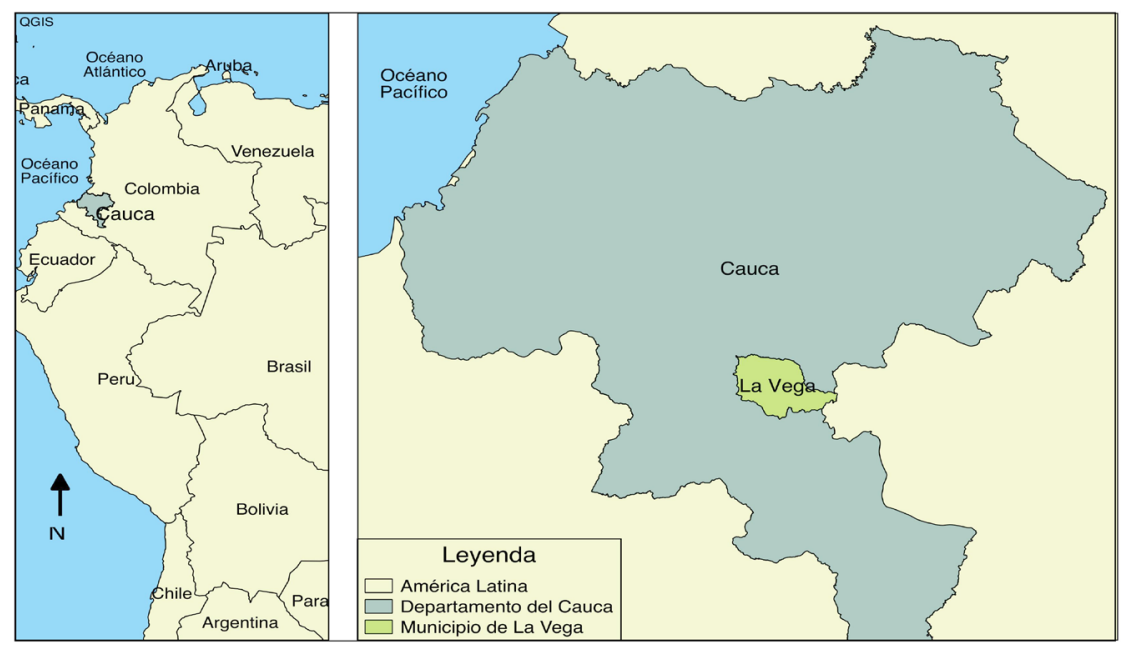

Fonte: Elaboração própria a partir do Sistema de Informação Geográfica para o Planejamento e Ordenamento Territorial (Colômbia) -SI-GOT.

${ }^{5}$ Colômbia é um país que se encontra dividido administrativamente em 32 departamentos, os quais Cauca faz parte deles; este departamento se encontra no sudoeste do país. Cauca da mesma forma que os outros departamentos se divide em municípios, corregimentos, veredas ssep.

${ }^{6}$ Ocupando, a nível mundial, o primeiro lugar em diversidade de aves e orquídeas; o segundo em plantas, anfíbios, peixes de água doce-aquícolas e borboletas; o terceiro em répteis e palmas; e o quarto lugar em mamíferos (Sistemas de Informação de Biodiversidade-SIB). 
No ano 2007, após um longo processo de trabalho comunitário foi formada por 39 famílias de camponeses produtores de mel e café, a Associação de Apicultores do Macizo Colombiano -APIMACIZO. A APIMACIZO se formou com a esperança de desenvolver alternativas produtivas prósperas e sustentáveis ${ }^{7}$, onde vem sendo realizado um trabalho constante para propiciar práticas sustentáveis de produção, obtendo os primeiros resultados tanto ecológicos como econômicos, como é o caso da criação e comercialização de uma marca de produtos apícolas onde não só se reconhecem suas práticas sustentáveis, mas também a qualidade do produto.

\section{Instrumento de coleta e análise dos dados}

Com o propósito de atingir os objetivos propostos no presente trabalho, foi realizada uma entrevista com um dos precursores da apicultura na região e que também faz parte atualmente da APIMACIZO. Para reconstruir a micro-história do processo do "surgimento" da apicultura nessa associação, a ferramenta foi a análise da "memória", da forma como menciona Acuña (2014), e trazendo para o nosso caso, uma vez que essa técnica de análise permite indagar a forma como se tem construído, no tempo, a apicultura, proporciona olhar a construção deste fato histórico e como é transmitido, além de entender como a atividade apícola transita dentro do passadopresente dos atores envolvidos.

A abordagem se faz metodologicamente a partir das narrações que fazem parte da memória de um ator, constituindo assim um modelo de referência que permite situar-se no grupo camponês (GODOI, 1999), como mencionou Brandão (1994), a memória não refere-se apenas às lembranças e nostalgias, são também sentimentos e recordações que vão formando a identidade própria.

\section{Resultados e Discussão}

\section{Breve relato do povo do Macizo Colombiano}

Compreender o processo da implementação e consolidação da atividade apícola no município da La Vega por parte da APIMACIZO, implica conhecer tanto o processo histórico como o processo cultural no qual emergiu e se fortaleceu esta atividade (WOORTMANN e WOORTMANN, 1997).

${ }^{7}$ Informação obtida na página web de APIMACIZO, acessada em 20 de abril de 2016. Disponível em: http:// apimacizo.jimdo.com/quienes-somos/
Neste sentido e seguindo os estudos de Godoi (1999), a relação entre a atividade apícola e a comunidade da APIMACIZO deve ser definida não só desde uma dimensão espacial, senão também de uma dimensão histórica, já que o grupo possui uma memória social e coletiva, uma história que é criada segundo os atores e as condições sociais nas quais estão imersos.

O Macizo Colombiano, assim como muitos dos povos que se reconhecem andinos, precisamente por serem povos assentados no que se denomina "Andes", tem uma característica quase identitária como é a "complementariedade ecológica"; guardando suas especificidades, esta característica explica as formas de adaptação das populações a determinado meio e as formas de acesso aos recursos naturais (DEL CAIRO, 2008 ). É desta forma como alguns pesquisadores descrevem as relações entre o ser e o produzir em uma região geograficamente estratégica como a mencionada; por exemplo, para Nates (2000, p.35) "o povo desta região vem conhecendo, construindo, fundando, usando, povoando, controlando e explicando seu território em termos sociais e ecológicos".

Uns dos primeiros relatos que fazem referência às relações sócioecológicas no Macizo foram feitas por Juan Friede (citação de Nates, 2000), falando dos "indígenas originários", sociedades agrícolas, semiestratificadas, rurais e familiares, que conseguiam obter variedade de produtos da terra graças aos diferentes "pisos térmicos" onde estavam assentados. Depois do processo de mestiçagem e da região ter-se tornado na época da colônia um ponto chave de extração de ouro, chega o auge do "capitalismo" em 1870, dando início à expansão cafeeira (SUÁREZ, 2007), época onde o café se converteu para os colombianos num produto exportável, sendo que na década de 1880 tornou-se o principal produto de exportação (SAFFORD e PALACIOS, 2002).

$\mathrm{O}$ auge do café implicou uma relação mais produtivista com a terra, nesta região o processo de desenvolvimento do café foi descrito como "marginal" e de pequenos produtores, quando comparada com outras regiões da Colômbia onde o grande e o médio produtor foram característicos, no Cauca se caracterizou por pequenas áreas com poucas extensões de terras dedicadas ao cultivo deste produto (TOCANCIPA et al., 2015 ). O desenvolvimento do café, portanto, esteve relacionado com fatores sociais, culturais e políticos, razão pela qual sua forma de produção foi descrita e

${ }^{8}$ Pisos térmicos fazem referência a um sistema de medição no qual se relaciona a altitude, clima com o tipo de produção agrícola. 
é entendida como "tradicional", no sentido de ser influenciada por práticas indígenas, conferindo-lhes particularidades no cultivo de café, como foi a combinação de culturas de "pancoger", os quais permitiram aproveitar os benefícios do solo e o uso de conhecimentos tradicionais (TOCANCIPA et al., 2015 ).

Por outro lado, Correa (1992) mencionou que no século XIX a cafeicultura configura-se não só como uma prática agrícola, senão também como uma forma de vida e subsistência local que caracterizou- se (e continua caracterizando-se) por ser uma atividade realizada por pequenos produtores que intercalam a semeadura de café com outras culturas em pequenas áreas. Posterior à introdução do café, em 1960, se deu o início à apicultura no município da La Vega- Cauca, prática que foi introduzida num contexto histórico diferente.

\section{Conhecendo a apicultura}

Las primeras abejas las trae el padre Armando que era de Suiza, en 1960, porque en esa época como tal apicultura no había. Él las tenia en la casa cural, atrás de la iglesia, por que eso es grande, eran abejas italianas y como la abeja italiana no es agresiva, las tenia allá. Él tenia un apiario con varias colmenas, y mi papá y un tío fueron aprendiendo ahí. Antes de irse el padre cuando lo trasladaron se las vendió a mi papá y le dejó explicando cómo era. Solo se producía miel, la cera sale por defecto, por la desoperculación pero no era un negocio. (Entrevista con Ariel Muñoz, 46 años)

A citação com a qual iniciamos este sub-item foi obtida numa entrevista feita a um dos integrantes de APIMACIZO, no ano 2016, que expõe o contato inicial que ele e sua família tiveram com a apicultura como um sistema produtivo do qual se obtiveram ganhos econômicos. Neste relato, é interessante a forma e os atores que fizeram possível o conhecimento e posterior apropriação de uma "nova" atividade produtiva e econômica para determinado grupo de camponeses desta região.

Neste caso específico, foi a igreja católica por intermédio de um de seus representantes, que não apenas transmite o "saber", como também permitiu o acesso aos meios de produção que posteriormente seriam incorporados à ${ }^{9}$ Pancoger é uma expressão utilizada para referir-se à semeadura de culturas de rotação e permanência curta que permitam garantir a alimentação de uma família camponesa. (TOCANCIPA et al., 2015) vida cotidiana destes habitantes. Neste sentido, como expõe Brandão (1986), todas as comunidades devem ser entendidas como parte de formações inclusivas onde sua própria realidade só acontece através de relações de produção de bens, serviços e com outros segmentos da sociedade. Portanto, é a partir do "saber" transmitido pelo padre Armando que esta atividade e o saber mesmo- é assimilada e apropriada de forma que passa a ser um "modo de vida".

Yo tenia 10 años cuando comencé ayudarle a mi papá porque como no eran agresivas, eso fue mas o menos en el 80, yo alcancé a trabajarle un tiempo antes de la africanización; y mas o menos en el 84- 85 llegó la africanización, yo creo que llegaron del Brasil por el Amazonas, por acá abajo, por el Caquetá, no se (...) La africanización aquí en la Vega llega en el 84-85, inclusive tuvimos que cambiar el equipo de manejo: ya tocó usar overol, ya tocó usar guantes largos, caretas más gruesas; porque antes simplemente se utilizaba una caretica en la nuca y sin guantes ni nada, eso era con la italiana (Ariel Muñoz).

Esta é uma versão de um momento chave para nosso interlocutor com relação à origem da apicultura nesta comunidade camponesa, esta deve ser entendida a partir de sua relação tanto com o presente quanto com o futuro, já que "as versões do passado são instrumentos fundamentais de definição da realidade atual e perspectivas futuras, mas que ao contrário não deixa de ser verdadeiro, isto é as perspectivas de mudanças futuras, também podem redefinir versões do passado" (GODOI, 1999, p. 29).

Os relatos trazem uma curta história de um dos atores de APIMACIZO, que narra diferentes momentos de sua vida na qual está relacionada a apicultura. Seguimos o argumento analítico proposto por Woortmann (1995), onde a autora busca compreender a reprodução camponesa, que se produz de geração em geração a partir da reconstrução da história, e não só de documentos senão através da "história oral" e a memória dos grupos pesquisados, isto nos permite identificar que a narração feita por Ariel tem um tempo específico, como é o processo de africanização, no qual é um processo que segundo Martinez (2006) chamou o "evento de 1983", sendo este um processo macro-histórico, no sentido de que assim como para Ariel, envolveu mudanças na forma de trabalhar na apicultura, foi um processo que também aconteceu a nível nacional. Por exemplo, nosso interlocutor mencionou que foi entre os anos 1984-1985 que ele evidenciou o processo 
de africanização das abelhas quando ajudava a seu pai na produção de mel; não obstante, Cornejo (1976) durante seu percorrido pela Colômbia, reportou as primeiras abelhas africanizadas no ano de 1977, no estado de Antioquia, quando ao narrar a anedota comenta que ao momento de revisar um apiário as abelhas foram agressivas, uma das características que diferencia as abelhas africanas das abelhas italianas. Desta forma, poderíamos utilizar para nosso caso específico também o termo que Godoi (1999) usa, "memória-mundo", o qual permite-nos situar nosso interlocutor dentro de uma ordem geral de fatos, unindo um acontecimento senão mundial, ao menos nacional, à sua vida, e sistematicamente a seu tempo presente como apicultor.

Esta memória de Ariel o coloca em um espaço e tempo específico, retomando a Woortmann (1995), essa temporalidade é levada também a um grupo como o é a família, por que foi ajudando seu pai na atividade apícola que ele lembra desse fato, onde o saber também é definido historicamente e faz parte das experiências vividas como grupo familiar, permitindo evidenciar que a história da apicultura em APIMACIZO também tem uma conotação familiar.

Embora não seja mencionado pelo interlocutor, na atualidade Ariel é um dos apicultores mais visíveis da associação, foi quem ajudou na capacitação de vários membros da APIMACIZO, assim como também outras associações da região, demonstrando que o saber não é só de uma pessoa, pois este é compartilhado, transmitido, herdado sem limitação alguma, por que como ele mesmo relatou numa parte da entrevista, "aquí todos somos amigos".

\section{O camponês da APIMACIZO: entendendo a família}

Se na seção anterior foi feita a reconstrução da primeira parte da história da apicultura, nesta seção pretendemos verificar como esta reconstrução histórica se dá na família, já que ao falar da prática de produção do mel não se pode desconhecer as relações que estão sendo tecidas ao redor dela. Portanto, parafraseando as palavras de Moura (1986), para adapta-las a nosso estudo de caso, podemos afirmar que a produção marcará de modo decisivo as formas de organizar a vida social do camponês, tudo isso pela união material e simbólica com a terra.

Quando na parte introdutória se questionou sobre a persistência do campesinato e como ainda suas relações prevalecem, a entrevista com o Sr. Ariel traz um elemento decisivo na continuidade do camponês, qual seja a família, a partir de sua história familiar que se relaciona diretamente com a produção apícola, sendo este um processo de transmissão entre pai e filho dentro de um núcleo familiar. Quando Chayanov explicou que "a composição familiar define ante todos os limites máximo e mínimo do volume de sua atividade econômica"(Chayanov, 1985, p.47), e que o volume da atividade econômica são todas as formas de atividade econômica da família, tanto na agricultura como na totalidade de atividades, ele evidenciou o papel da família como eixo organizador dentro do campesinato, assim como a família como base de sua reprodução.

É precisamente na família onde nosso interlocutor narra sua colaboração no processo de aprendizagem e na prática da apicultura, sendo a figura paterna quem desempenha um papel hierárquico dentro desta, já que é a partir da experiência do manejo apícola de seu pai que ele, Ariel, consegue apreender um sistema de produção, mantendo-se a relação pai e filho. Portanto, "esse caráter familiar se expressa nas práticas sociais que implicam uma associação entre patrimônio, trabalho e consumo, no interior da família, e que orientam uma lógica de funcionamento específica" (Wanderley, 2003, p.45), organizando-se em função da experiência no trabalho, a qual implica hierarquia. (WOORTMANN, 2001).

No caso de nosso interlocutor, a transmissão da experiência tem seu fio condutor no saber da atividade apícola, a qual dentro de sua família começa com a transmissão por parte do padre Armando, para depois torna-se num saber adaptado e direcionado pelo pai; é dizer, de uma geração a outra a partir do próprio trabalho, através do que Woortmann e Woortmann (1997) denominam saber-fazer ${ }^{10}$, um saber que se gestou na família por parte da figura paterna, o qual não é só uma transmissão de técnicas na produção, senão aquele que vai envolver valores, construção de papéis e hierarquias dentro do grupo familiar; esse saber, portanto, vai ser hierárquico e determinará o controle sobre o grupo e na família onde se reproduz.

É nesta transmissão de saber onde conseguimos entender a narração de nosso interlocutor a partir do mencionado por Woortmann e Woortmann (1997), para quem a produção é central na reprodução do grupo visto como um todo; e se a produção é central para a reprodução, é (neste caso) pelo trabalho que se construí a família; em outras palavras, é pelo saber "técnico" que ela se constitui, razão pela qual na apicultura feita pela APIMACIZO

"Denominação que é produto do trabalho feito no seu livro "o trabalho da terra" onde analisa o trabalho agrícola dos camponeses nordestinos, sendo este não só espaços agrícolas, senão espaços sociais e de gênero, mostrando a lógica interna do campesinato. 
não apenas há a produção de mel, como também ao longo desse processo se produz valores, saberes e cultura. Por mais que se pense em sistemas de produção, estes não são vazios, são espaços socialmente estruturados segundo as relações do saber Brandão (1986), o qual pode ser adquirido a partir de uma instituição como foi a igreja para nosso caso no começo da apicultura, para depois converter- se em um sistema produzido e reproduzido dentro da família, como menciona Wolf (1990, p.24), a família “além de funcionar com a máxima eficácia ao mínimo custo, se adapta otimamente às mudanças das condições que definem e delimitam sua existência", e foi na prática apícola que eles decidiram convertê-la em um modo de vida.

\section{Conclusões}

A memória como ferramenta para a reconstrução da história permitiu relacionar fatos locais com fatos nacionais como pôde ser observado no processo de africanização das abelhas.

A apicultura apesar de ser uma atividade que foi apreendida através da igreja, foi aceita e adaptada por parte dos camponeses, incorporando-a dentro de suas práticas produtivas como complementária, tornando-se num modo de vida.

O saber da atividade apícola ao ser transmitido de geração a geração está diretamente ligado às relações com o trabalho e à apropriação do conhecimento entre as gerações. Muito mais do que técnica, a prática apícola entre os camponeses tem um significado maior, diretamente associado à construção de valores, saberes e cultura.

\section{Referências Bibliográficas}

ACUÑA, Olga. El Pasado: Historia o Memoria. Historia y Memoria, Tunja- Colombia, n.9, p. 57-87, jul. 2014.

BRANDÃO, Carlos. Saber e ensinar : três estudos de educação popular. Campinas: Papirus, 2da edição, 1986. 187 p.

BRANDÃO, Carlos. O sentimento do mundo: memoria, destino e cenários de vida entre errantes mineiros. In: MENESES, A. et al. As Faces da memoria. Campinas: UNICAMP, 1994, p. 61-84.
CHAYANOV, Alexander. La organización de la unidad económica campesina. Buenos Aires, Argentina: Ediciones Nueva Visión, 1985. 342 p.

CORNEJO, Luis. Informe final sobre diagnostico de la situación de la apicultura colombiana y bases para su desarrollo. Centro interamericano de promoción de exportaciones CIPE, 1976

CORREA, Claudia. El desarrollo de la caficultura en el Cauca. In:

Ensayos sobre Economía Cafetera, Bogotá: Federación Nacional de Cafeteros, 1992, p. 133-147.

DEL CAIRO, Carolina. El Macizo Colombiano: Una región en permanente Construcción. Editorial: Fundacion espacio abierto, 2008. $194 \mathrm{p}$.

FALS BORDA, O. Retorno a la tierra (Historia doble de la Costa 4). Bogotá: Universidad Nacional de Colombia-Banco de la República-El Áncora Editores.2002. 234p.

FORERO, Jaime et al. El campesino colombiano: entre el protagonismo económico y el desconocimiento de la sociedad, Bogotá: Pontificia Universidad Javeriana, 2010. 143p.

GODOI, Emilia.O trabalho da memoria: cotidiano e historia no sertão do Piaui. Campinas: Editora da Unicamp,1999. 165 p.

IDEAM. INSTITUTO DE HIDROLOGÍA, METEOROLOGÍA Y ESTUdios AMBIENTALES. El Macizo Colombiano y su área de influencia inmediata : diagnóstico, descripción de la unidad regional y propuesta de delimitación. v.1.Santa fe de Bogotá, Colombia, 1999. 428 p.

MARTÍNEZ, Telmo. Diagnostico de la actividad apícola y de la crianza de abejas en Colombia. Bogotá: Ministerio de Agricultura y Desarrollo Rural \& Instituto Interamericano de Cooperación para la Agricultura (IICA), 2006. 121 p.

MINTZ, Sidney. Dulzura y poder: el lugar del azúcar moderna en la 
historia moderna. México: Siglo XXI editores. 1996. 299 p.

MOURA, Margarida. Camponeses. São Pulo: Editora Ática, 1986. 78 p.

NATES, Beatríz. DE LO BREVO A LO MANSO: territorio y sociedad en los Andes Macizo Colombiano. Quito, Ecuador: Ediciones Abya-Yala, $2000.333 \mathrm{p}$.

PALACIOS, Marco; SAFFORD, Frank. Colombia : país fragmentado sociedad dividida, su historia. Bogotá, Colombia: Editorial Norma, 2002. $745 \mathrm{p}$.

PNUD. PROGRAMA DE NACIONES UNIDAS. Colombia rural. Razones para la esperanza. Informe Nacional de Desarrollo Humano 2011. Bogotá, Colombia.2011. 92 p.

SALGADO, Carlos. Procesos de desvalorización del campesinado y antidemocracia en el campo colombiano. In: FORERO, Jaime et al. El campesino colombiano: entre el protagonismo económico y el desconocimiento de la sociedad, Bogotá: Pontificia Universidad Javeriana, 2010, p. 15-29.

SIB. SISTEMA DE INFORMACIÓN SOBRE BIODIVERSIDAD DE COLOMBIA. Biodiversidad en Cifras. Disponible en: http://www. sibcolombia.net/web/sib/cifras,Acesso em: 15 nov. 2015.

SUÁREZ, Aurelio. EI modelo agrícola colombiano y los alimentos en la globalización. Bogotá, Colombia: Ediciones Aurora, 2007. 221 p.

TOCANCIPÁ, Jairo et al. Cafeteros del Macizo Colombiano: re-creando historias en tiempos de crisis, corregimiento de El Paraíso (Sucre, Cauca). Popayán : Sello Editorial Universidad del Cauca, 2015. 196 p.

WANDERLEY, Maria. Agricultura familiar e campesinato: rupturas e continuidades. Estudos Sociedade e Agricultura. Rio de Janeiro : CPDA/ MAUAD, 2003, n.21, p. 42-6.
WOORTMAN, Ellen. Herdeiros, Parentes e Compadres : colonos do Sul e sitiantes do Nordeste, Brasília: UNB, 1995. 336 p.

WOORTMANN, Ellen. O saber camponês: práticas ecológicas tradicionais e inovações. In: Godoi, E.; Menezes, M.; Marin, R. Diversidade do campesinato: expressões e categorias. Sao Paulo: Editora UNESP, 2009, v.2, p. $119-130$

WOORTMANN, Klaas. O modo de produção doméstico em duas perspectivas: Chayanov e Sahlins, Brasília: Série Antropologia, UNB. n. 293, 2001. 28 p. 